Review of Sociology 28(4): S166-S190.

\title{
Diversity management and gender equality outcomes in research, development and innovation organisations: Lessons for practitioners ${ }^{1}$
}

\author{
Katalin Tardos ${ }^{2}$ - Veronika Paksi ${ }^{3}$ \\ https://doi.org/10.51624/SzocSzemle.2018.4.8 \\ Manuscript received: 7 November 2018 \\ Modified manuscript received: 20 December 2018 \\ Acceptance of manuscript for publication: 31 December 2018
}

\begin{abstract}
Understanding the impact of various diversity management (DM) practices in terms of their effectiveness in achieving desired outcomes within the organisation is a prevalent research gap in the general DM literature and the new stream of literature on DM in the research, development, and innovation (RDI) sector. Therefore, this article reviews the literature on gender diversity practices in RDI workplaces and how DM contributes to gender equality outcomes. For this purpose, we introduced a conceptual framework to demonstrate the interrelatedness of the forms and reasons for gender inequality, and the choice of DM practices and their outcomes. Moreover, we compiled an extensive list of DM practices for practitioners related to how to address the different forms and underlying reasons for gender inequality. Finally, by comparing the literature on DM outcomes in the business and the RDI sector, we concluded that research on measuring the outcomes of DM practices was less developed for RDI organisations, but gaps of knowledge on the outcomes of DM practices prevailed in both sectors. Organisational contexts in which specific diversity practices were implemented had a significant role in determining their effectiveness, highlighting the relevance of the institutionalist theory.
\end{abstract}

Keywords: Gender Equality, Diversity Management, RDI sector, Academia, Diversity Management Outcomes

\section{Introduction}

In the past decade, increasing attention has been devoted on behalf of researchers and policy-making governmental and international organisations to the institutionalisation of diversity management (DM) practices in research, development and innovation (RDI) organisations. Following diversity and inclusion policy developments in the private business sector, the necessity to more effectively

1 Acknowledgements: The research was supported by the National Research, Development and Innovation Fund (NKFI K 116102).

2 Katalin Tardos is Professor at International Business School and Senior Research Fellow at the Centre for Social Sciences, Institute for Sociology, Hungarian Academy of Sciences.

3 Veronika Paksi is Junior Senior Research Fellow at the Centre for Social Sciences, Institute for Sociology, Hungarian Academy of Sciences. 
manage various forms of discrimination and inequalities, especially gender inequality in higher education institutions, research performing organisations (RPOs), and funding organisations (RFOs) within the RDI sector, gradually manifested on research and policy agendas (European Commission 2012; European Parliament 2015; OECD 2017; Prügl 2011; Timmers - Willemsen - Tijdens 2010).

Historically, the main streams of research on discrimination, equal opportunities, and diversity and inclusion research have focused on groups related to gender and race (Abrams 1989; Cleveland et al. 2000; Eckstein - Wolpin 1999). Despite of the long history of researching and managing gender inequality at workplaces and the significant improvements made in many countries and industries in the past decades (European Union 2017; OECD 2017), typical forms of gender inequality prevail in the under-representation or gap in employment in general, and in certain industries and jobs in particular, leading to horizontal segregation. Moreover, horizontal segregation is often combined with vertical segregation manifesting in slower career advancement of women and under-representation in top managerial positions and other decisionmaking bodies such as boards and management committees (Choudhury 2015; Dämmrich - Blossfeld 2016; Kacprzak 2014; Kim - Starks 2016; Meulders et al. 2010). Moreover, a persistent gender-based wage gap has been observed that is disadvantageous to women (Card - Cardoso - Kline 2015; Kangasniemi - Kauhanen 2013; Mihaila 2016). This wage gap is often coupled with a greater risk for an unsecure employment relationship and a fixed-term type of contract, leading to further disadvantages and potential precariatisation. (Gash - McGinnity 2007; Standing 2011).

The RDI sector is not an exception to the persistence of significant levels of gender inequality. In RDI organisations gender equality is challenged by tall hierarchies, rigid traditional career ladders, blindness or low awareness of gender inequalities, and masculine/gendered organisational culture, to name some of the barriers to gender equality. To substantiate the extent of the problem, for instance, the European Commission's publication (2016) on the level of gender inequality within the RDI sector of European Member States reveals that corresponding to the general tendencies of gender inequality in the economy, women are also significantly underrepresented among researchers, and that all other forms of gender inequality, for example, the wage and security gap (fixed-term contracts) and horizontal and vertical segregation, imply that barriers in career advancement and lower representation in decision-making bodies prevailed in the investigated time span, between 2003 and 2015 (Bryson 2004; European Commission 2016; Poggio 2017). In addition to the classic forms of gender inequality, specific types of disadvantages have been identified for women researchers, for example, a lower chance of winning research grants or obtaining grants of smaller value (European Commission 2009). Nevertheless, gender equality is important for social justice and ethical reasons, as well as economic and organisational performance considerations in both the business and RDI sector. 
As a response to the evidence for the persisting gender inequalities, policy measures and goals have been established for the European Research Area (ERA) to improve the gender equality in academic careers, remove possible biases and discrimination, ensure equal opportunities, increase the gender balance in decisionmaking bodies, and integrate the gender dimension in research content (European Commission 2012). At the organisational level, RDI organisations are encouraged (or obliged by law) to establish plans to promote gender equality and introduce various initiatives to promote gender equality. However, according to ERA Facts and Figures 2014 , only $36 \%$ of RPOs in the EU28 have adopted gender equality plans thus far (European Commission 2015).

Managing gender inequalities can be embraced by the broader concept of DM because one of the main objectives of DM is to increase the inclusion of different, and often disadvantaged, minority groups (e.g., women) into the workforce and nurture diversity to the benefit of the organisation (Kandola - Fullerton 1998). Nevertheless, relatively little research has been performed on how the introduction and institutionalisation of DM practices lead to DM outcomes, especially in the RDI sector.

Within the stream of literature on business organisations, most of research has investigated the link between DM practices and overall organisational performance (Bleijenbergh - Peters - Poutsma 2010; Herring 2009), that is, the business case of diversity; by contrast, little is known regarding more specific diversity outcomes such as which diversity initiatives lead more effectively to the targeted diversity outcomes. Understanding the impact of various DM practices, including those regarding gender diversity, in terms of their effectiveness in attaining desired outcomes within the organisation is a prevalent research gap in the general DM literature and the new stream of literature on DM in the RDI sector (Kulik 2014). Therefore, this article aims to review the literature on DM in the RDI sector related to research on the effectiveness of DM initiatives and, in particular, DM aiming to increase gender equality.

The research question this article attempts to answer is as follows: How does DM contribute to gender equality in RDI workplaces? More specifically, through the analysis of findings in the literature, we address the following. First, we address the theoretical background of DM; second, we review empirical findings on the factors influencing the adoption of diversity initiatives in organisations; third, we address how RDI organisations promote gender equality and diversity among researchers with DM practices; forth, we address DM initiatives from the perspective of attaining targeted gender equality outcomes in RDI organisations compared to the business sector.

For the purpose of this article, a conceptual framework was established to demonstrate the interrelatedness of the forms of and reasons for gender inequality and the choice of DM practices and their outcomes. This framework represents the logic of the analysis in the remainder of this article. 
Figure 1: Interrelatedness of the forms and reasons for gender inequality, the choice of DM practices and their outcomes

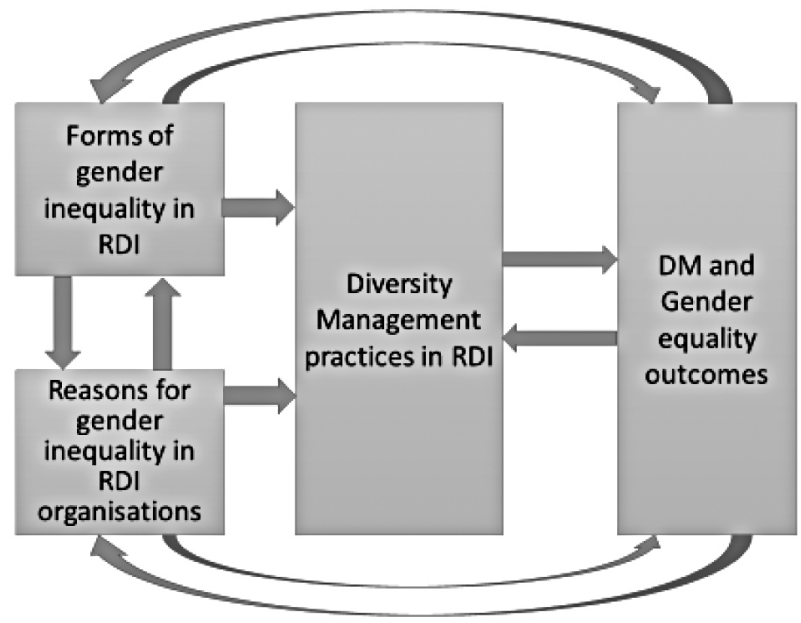

\section{Methodology}

This article adopted the traditional, narrative literature review approach as opposed to systematic literature reviews (Ferrari 2015; Grant - Booth 2009). Narrative literature reviews "are aimed at identifying and summarizing what has been previously published, avoiding duplications, and seeking new study areas not yet addressed" (Ferrari 2015: 230). For the purpose of the narrative literature review-, the following search terms were used in the databases of Ebsco, Jstor, Emerald, Sciencedirect, and Google Scholar: 1) Theories/theoretical frameworks of DM; 2) DM in Academia/ RDI/Higher Education/Universities/Science; 3) Gender Diversity in Academia/RDI/ Higher Education/Science; Gender Inequality in Academia/RDI/Higher Education/ Universities/Science; 4) Gender Equality in Academia/RDI/Higher Education/ Universities/Science; 5) Gender Discrimination in Academia/RDI/Higher Education/ Universities/Science; 6) Effectiveness of DM in Academia/RDI/Higher Education/ Science; 7) Outcomes of DM in Academia/RDI/Higher Education/Science.

English language articles have been selected based on whether they include theoretical or empirical findings related to the effectiveness of DM practices and gender equality in the context of academia and RDI organisations. In principle we targeted articles published after 2010, however included older ones if assessed as critical for the review, especially related to DM history and theories. Overall, 70 articles have been selected. Related to the date of publication more than two-thirds of the articles were published between 2010 and 2018. Concerning the geographic representation of authors cited, almost half of the articles' authors were affiliated within the United States. The dominant role of US researchers on DM was especially prevalent in the period before 2010. For articles published in 2010 and beyond, authors were dominantly 
originating from Europe, with countries represented as the United Kingdom, the Netherlands, Belgium, Ireland, Norway, Denmark and Italy. Furthermore, linked to a strong Anglo-Saxon gender equality tradition, Australia was also represented in the sample of selected articles. While narrative literature reviews typically address one or more research questions/ topics, as the selection criteria for inclusion of the articles may not be explicitly defined, the selection and evaluation biases are not known, therefore potential subjectivity and non-reproducibility constitute a limitation of the non-systematic narrative literature review. (Ferrari 2015).

\section{Theories on DM}

DM emerged as a new business paradigm in the beginning of the 1990s by claiming that the diversity of the workforce could be a strategic asset of an organisation (linked to the resource-based view of the firm), which could lead to competitive advantage if managed well (Kelly - Dobbin 1998; Robinson - Dechant 1997; Zanoni et al. 2010). Many definitions exist for DM practices. Yang and Kanrad define DM as "Any formalized practices intended to enhance stakeholder diversity, create a positive working relationship among diverse sets of stakeholders, and create value from diversity" (Yang - Konrad 2011: 7-8). This strategic approach to the notion of diversity resulted in a completely new understanding of differences in organisations. Diversity was not understood only on a group membership basis, but much more on the basis of individual attributes.

Linked to this individualised nature of diversity, Cox's (1991) model of the multicultural organisation suggests that organisations must become multicultural in the sense that employees do not feel pressure to assimilate, can bring their differences and identities to the workplace, and can contribute their full potential to the benefit of the organisation. In line with the logic of Cox's multicultural organisation model (1991), Ely and Thomas (2001) advocate for a new learning and integration paradigm of diversity: if organisations encourage their employees to address organisational problems through the context of their demographic and cultural qualities, companies could capitalise on the learning and innovation resulting from diversity, an outcome of significant importance in the RDI sector.

Starting in the mid-1990s, a critical reaction to the new management paradigm of DM emerged as a response to the new conceptualisation of equal opportunity employment policies by business organisations. Zanoni et al. (2010) identify three major critiques of the DM literature: 1) identities are conceptualised as fixed, monolithic, and easily measurable categories, 2) the tendency to reduce the significance of organisational and societal contexts in shaping the meaning of diversity, and 3) a clearly managerial perspective and theorising power have been inadequately considered. 
Critical DM theories have been based on theories such as post-structuralism, discourse analysis, cultural studies, post-colonialism, institutional theory, and labour process theory (Zanoni et al. 2010). As a contribution to the critical DM literature, Yang and Konrad (2011) differentiate among superficial and substantive diversity management practices: '...superficial diversity management efforts are those which are relatively narrow and implemented in isolation from other organisational systems and processes. Substantive DM efforts that are integrated across multiple organisational subsystems have more positive outcomes for individuals and organisations' (Yang - Konrad 2011: 16). Likewise, aiming to uncover the real value of DM practices, Tatli (2010) emphasises the necessity to adopt a multi-layered exploration to diversity management related to discourse, practice, and practitioners and identifies an important gap between diversity discourse and the actual quality of diversity practice (Tatli 2010).

Factors influencing the adoption of diversity initiatives in organisations

An important question to answer is as follows: What factors affect the adoption of diversity initiatives in organisations? Dobbin, Kim and Kalev (2011) identify four potential reasons why some employers embrace DM innovations and others do not: the effects of external pressure, internal advocates, functional demand, and corporate culture on the adoption of corporate equal opportunity and diversity programmes. Further findings have reinforced that women's participation in management, open corporate culture, and formal commitments to equality-related social norms promoted the adoption of diversity programmes.

The role of organisational culture and diversity climate in adopting diversity practices has been investigated by Herdman and McMillan-Capehart (2010). Herdman and McMillan-Capehart (2010) in their survey of 3,578 employees across 163 hotels measure the relationship between diversity programmes, managerial values, and diversity climate in the organisation, and observe support for the relationship between the deployment of diversity programmes and the diversity climate residing in the organisation. Furthermore, collective managerial relational values [high commitment to human resource (HR) policies] are predictive of the adoption of diversity initiatives.

Based on a sample of 248 medium-sized to large-sized organisations using a timelagged survey and archival data, Ali and Konrad (2017) tested a moderated mediation model focusing on antecedents (i.e. top management team gender diversity) and consequences (i.e. performance) of Diversity and Equality management (DEM) systems. The findings provide full support for the hypothesis that a gender-diverse top management team is positively associated with DEM systems.

Thus, the evidence from the research demonstrates that an open organisational culture, a positive diversity climate, a gender-diverse top management team, a high commitment to HR policies, and formal commitments to equality-related social norms are the most important antecedents for the implementation of DM practices. 


\section{DM and gender equality practices in RDI organisations}

DM and gender equality practices can target different manifestations and forms of gender inequality and the underlying reasons leading to those inequalities. DM and gender equality practices have been grouped under different categories; however, they share the characteristics of individual and organisational level initiatives. Moreover, it is necessary to differentiate between practices aiming to reduce inequalities in terms of providing enablers or reducing barriers to counter inequalities from practices that concentrate on the effective functioning of the DM system, for example, having a diversity and equality plan, a diversity taskforce, or regularly monitoring results. In the next section, we review research on the implementation of a variety of gender equality practices in the context of RDI organisations and categorise the potential gender equality initiatives and practices in relation to the forms and underlying reasons for gender equality in RDI.

Timmers, Willemsen and Tijdens (2010) study whether policies to increase women's share among university professors between 2000 and 2007 were effective in the 14 universities of the Netherlands. For this purpose, the authors categorised 19 gender equality policy measures into three groups of factors: individual, cultural, and structural or institutional. (Figure 2) Within the individual perspective mentoring, coaching and training women were the most frequent practices applied by Dutch universities. Regarding the initiatives addressing cultural aspects of the institution, expressing responsibility and commitment to gender equality by top management was found to be the most common action. Finally, among practices addressing structural and institutional levels, establishing accountability for recruitment is the most widely applied practice at universities in the Netherlands (Timmers - Willemsen - Tijdens 2010).

Figure 2: Grouping of gender equality policy measures by individual, cultural, and structural categories. Source: based on (Timmers - Willemsen - Tijdens 2010).
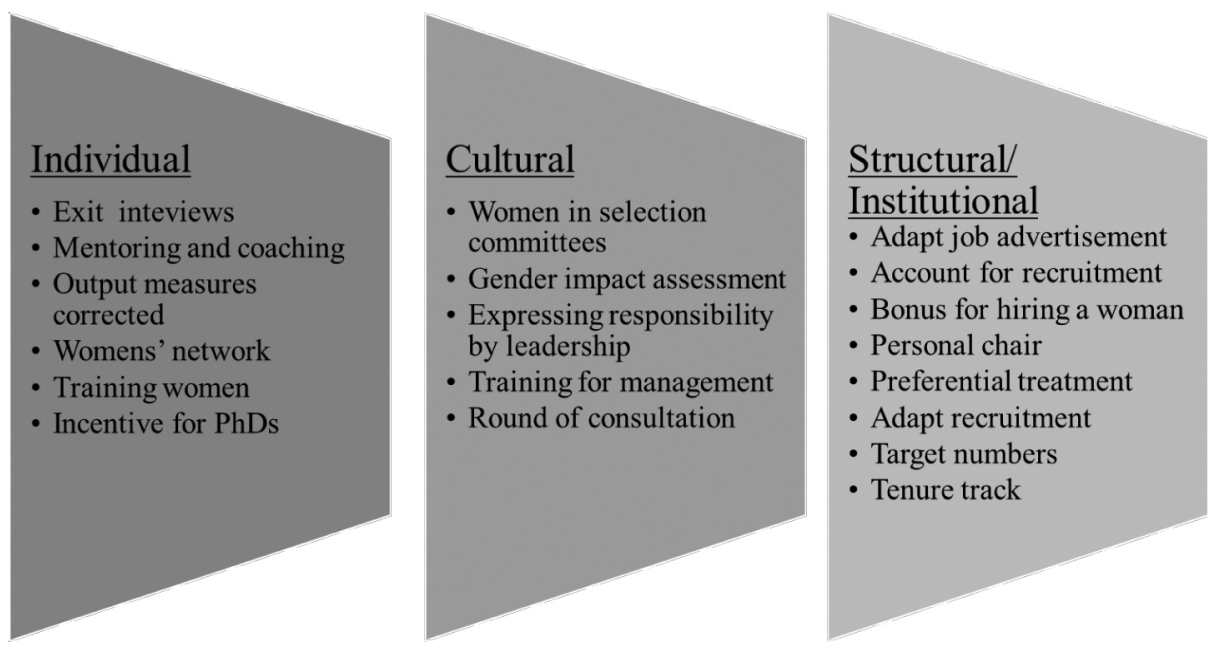
Another example of comprehensive research on implementing gender equality practices and assessing the effectiveness of the organisational transformation process is in the Science and engineering field within 19 US universities (Bilimoria - Joy Liang 2008). In the framework of the NSF ADVANCE IT funding programmes, the 19 universities introduce pipeline initiatives to increase the inflow of women into the pipeline and improve the institutional structures and processes related to academic career transition points and to better equip women to successfully progress within the pipeline (mentoring, coaching, networking, education and training, career and professional development, leadership development, and special funding and opportunities) and climate initiatives to improve the awareness and practices of male colleagues through education, training, and development; engage in efforts to make departments more equitable and transparent; and increase organisational awareness of diversity and inclusion topics (Bilimoria - Joy - Liang 2008: 427).

On the one hand, the study stresses the importance of institutionalising the new organisational practices and the necessity to integrate the new structures, positions, policies, and resources into the organisational processes; on the other hand, the researchers emphasise the role of internal and external facilitating factors such as senior administrative support and involvement, widespread collaborative leadership and synergistic partnerships, clear visions, flexible paths and milestones, transparency regarding actions and outcomes, and best-practice sharing with peer organisations (Bilimoria - Joy - Liang 2008). In addition to the aforementioned diversity practices, the authors indicate the significance of systematically tracking key indicators of gender equality, conducting climate (satisfaction) surveys, benchmarking studies, and evaluating and monitoring interventions and their outcomes.

A new, ongoing Horizon 2020 project, the Evaluation Framework for Promoting Gender Equality in Research and Innovation (EFFORTI), identifies requirements for the development of gender equality in RDI organisations: 1) a clear specification of aims and problems; 2) clear responsibilities for all stakeholders involved; 3) effective implementation mechanisms implying a good balance of individual and structural measures, and relevant knowledge regarding evaluation methodologies, tools, statistics for monitoring progress; 4) a sufficient amount of resources allocated to the organisational interventions; and 5) sanctions in cases of non-compliance and the role of RFOs in supporting gender equality in organisations and in the integration of gender dimension in research and teaching (EFFORTI 2017). The comparative study acknowledges that evaluation traditions vary across European countries regarding gender equality.

In 2018, the League of European Research Universities (LERU) published a paper on how universities' RPOs and RFOs can implement sustainable change to decrease the level of unconscious implicit gender bias in academia when important career decisions are made, such as recruitment, selection, retention and advancement, and the allocation of research funding (Gvozdanović - Maes 2018). The report claims that 
implicit gender bias has a significant role in the creation of the leaky pipeline, and although the discrepancy between idealised meritocratic beliefs in academia and the de facto functioning of assessment procedures is not easy to recognise, organisations can plan and implement meaningful interventions in three areas.

The first group of possible actions relate to showing leadership, vision, and strategy and eliminating gender bias. To manage the process of culture change in the organisation LERU recommends implementing leadership training on all levels.

Regarding the second group of possible actions, the report on how to overcome the implicit gender bias recommends implementing organisation-wide structural measures in addition to individual measures. Practices could include 'universitywide reviews of job advertisements, appointing gender "vanguards" in all academic staff evaluation and selection committees, developing guidelines to make selection procedures transparent, using external evaluators, briefing evaluation committees immediately before the assessment, providing mandatory or voluntary training on bias to various staff categories, developing fact sheets, online resources and other information tools to increase knowledge about bias' (Gvozdanović - Maes 2018: 4).

The third group of possible actions consists of finding means to ensure the effective implementation of actions across the institution by maintaining transparency, defining accountability for outcomes, and monitoring. A tool for the successful monitoring of progress could be the multi-annual gender action plan or annual reporting (Gvozdanović - Maes 2018: 4).

The LERU has also established nine general recommendations for RDI organisations regarding how to decrease implicit bias: 1) Have regular monitoring of potential gender bias in place in organisational structures and processes. 2) Examine critical areas of potential bias and define measures for countering bias. 3) Gather expertise and organise gender bias training in various formats, including the possibility of anonymous training. 4) Make recruitment and/or funding processes be as open and transparent as possible and be merit-based. 5) Monitor potential bias in the language used in the recruitment processes. 6) Eliminate the gender pay gap and monitor progress. 7) Compensate employees for parental leave and ensure the process is bias-free by extending fixed-term positions or calculating the leave administratively as active service and exempt from publication expectations. 8) Monitor precarious contracts and part-time positions for gender-based differences and correct inequalities. 9) Properly represent women in all leading positions and ensure that leadership and processes around leadership are free from bias. (Gvozdanović - Maes 2018).

To synthesise the wide variety of DM and gender equality practices in RDI organisations, we sorted these potential practices based on the forms and manifestations of gender inequality and the reasons underlying these inequalities; thus, Tables 1 and 2 provide RDI organisation practitioners a practical summary for potential interventions. 
Table 1: Grouping of potential DM and gender equality practices based on forms of gender inequality in RDI organisations

\begin{tabular}{|c|c|}
\hline $\begin{array}{l}\text { Forms of gender inequality } \\
\text { in RDI organisations }\end{array}$ & DM practices to address different forms of gender inequality \\
\hline $\begin{array}{l}\text { Gender gap/under- } \\
\text { representation of women } \\
\text { in RDI organisations and } \\
\text { science }\end{array}$ & $\begin{array}{l}\text { - } \quad \text { Building partnerships with NGOs and primary and secondary } \\
\text { educational institutions to promote scientific careers for girls } \\
\text { - } \quad \text { Reaching out to university students: internships, open days, } \\
\text { building partnerships with universities and RPOs } \\
\text { - } \quad \text { Increasing employer attractiveness for women } \\
\text { - } \quad \text { Providing training and mentoring prior to recruitment } \\
\text { - } \quad \text { Adapting the recruitment process: adapt job advertisement, } \\
\text { accountability for recruitment and selection decisions, revise } \\
\text { recruitment methods to have gender balance on shortlists } \\
\text { - Change selection tools: Transparent application and selection } \\
\text { procedures; prioritising research quality over quantity in selection } \\
\text { criteria; using partially anonymised CVs; briefing selection } \\
\text { committees about bias pitfalls before the assessment; including } \\
\text { external observers and evaluators in these processes; evaluating } \\
\text { all selection and promotion procedures before appointments are } \\
\text { completed (Gvozdanović - Maes 2018: 18) } \\
\text { Initiatives for retention: exit interviews and climate (employee } \\
\text { satisfaction) surveys (employee satisfaction) surveys to measure } \\
\text { key factors influencing retention, and integrating relevant } \\
\text { measures into the diversity and gender equality plan (DGEP) }\end{array}$ \\
\hline $\begin{array}{l}\text { Employment relationship, } \\
\text { type of contract }\end{array}$ & $\begin{array}{l}\text { - } \quad \text { Regular gender impact assessment of types of contract and the } \\
\text { nature of the employment relationship }\end{array}$ \\
\hline $\begin{array}{l}\text { Horizontal segregation: } \\
\text { under-representation in } \\
\text { certain disciplines (STEM) }\end{array}$ & 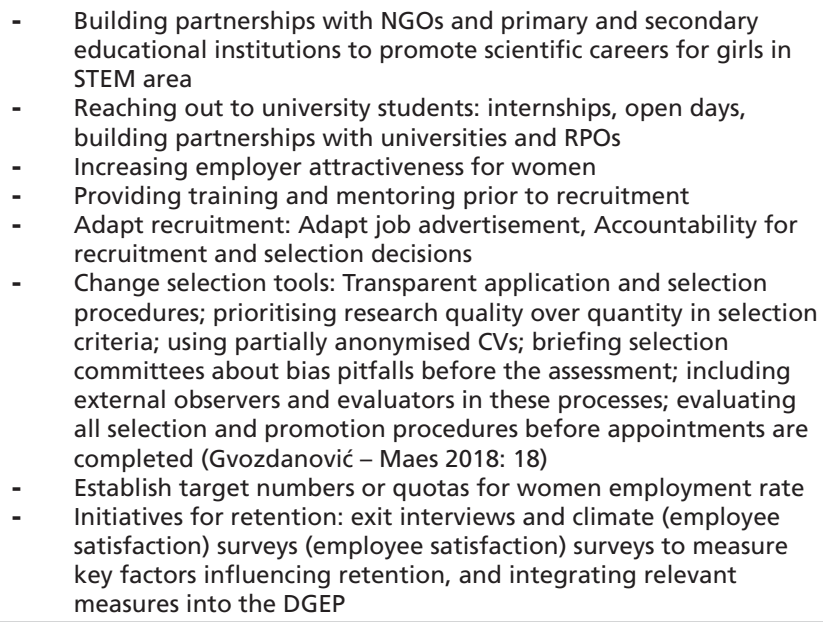 \\
\hline
\end{tabular}




\begin{tabular}{|c|c|}
\hline $\begin{array}{l}\text { Forms of gender inequality } \\
\text { in RDI organisations }\end{array}$ & DM practices to address different forms of gender inequality \\
\hline $\begin{array}{l}\text { Vertical segregation: slower } \\
\text { career advancement, } \\
\text { under-representation in } \\
\text { managerial positions }\end{array}$ & $\begin{array}{l}\text { - } \quad \text { Mentoring and coaching } \\
\text { - } \quad \text { Training and development programmes for women (e.g. for self- } \\
\text { branding, assertiveness, leadership skills, networking) } \\
\text { Developing women's network (early career, single parent, } \\
\text { working parents, and other diversity groups) } \\
\text { - } \quad \text { Incentives for PhD holders } \\
\text { - } \quad \text { Selection tools: Transparent promotion procedures; prioritising } \\
\text { research quality over quantity in selection criteria; briefing } \\
\text { promotion committees about bias pitfalls before the assessment; } \\
\text { including external observers and evaluators in these processes; } \\
\text { evaluating all selection and promotion procedures before } \\
\text { appointments are completed (Gvozdanović - Maes 2018: 18) } \\
\text { Identifying women in middle management who have the } \\
\text { potential to become future senior leaders } \\
\text { - } \quad \text { Including women in selection committees } \\
\text { - } \quad \text { Expressing responsibility by leadership } \\
\text { Training for management at all levels on unconscious bias (middle } \\
\text { and top) } \\
\text { Establishing target numbers or quotas for women for each career } \\
\text { stage } \\
\text { Changing job structure: part- time positions for professors } \\
\text { (Gvozdanović - Maes2018: 4) }\end{array}$ \\
\hline $\begin{array}{l}\text { Vertical segregation: under- } \\
\text { representation in decision- } \\
\text { making positions }\end{array}$ & $\begin{array}{ll}\text { - } & \text { Including women in selection committees } \\
\text { - } & \text { Expressing responsibility by leadership for gender equality } \\
\text { - } & \text { Training for management at all levels on unconscious bias (middle } \\
\text { and top) } & \\
\text { - Establishing target numbers or quotas for women's } \\
\text { representation in decision-making positions }\end{array}$ \\
\hline $\begin{array}{l}\text { Wage gap, differentials, } \\
\text { wage equity }\end{array}$ & 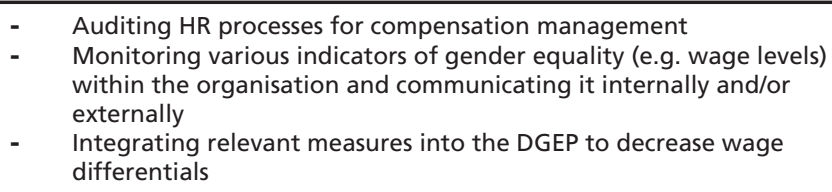 \\
\hline $\begin{array}{l}\text { Lower chance of winning } \\
\text { research grants }\end{array}$ & $\begin{array}{ll}- & \text { Including women in selection committees } \\
- & \text { Training for assessor committee members on unconscious bias } \\
\text { - } & \text { Regular gender impact assessment of grant decisions } \\
\text { - } & \text { Forming gender-diverse research teams for grant applications }\end{array}$ \\
\hline $\begin{array}{l}\text { Smaller size of research } \\
\text { grants }\end{array}$ & $\begin{array}{ll}- & \text { Including women in selection committees } \\
\text { - } & \text { Training for assessor committee members on unconscious bias } \\
\text { - } & \text { Regular gender impact assessment of grant decisions }\end{array}$ \\
\hline
\end{tabular}

Sources: (Armstrong et al. 2010; Gvozdanović - Maes 2018; Timmers - Willemsen - Tijdens 2010; Winchester - Browning 
Table 2: Grouping of potential DM and gender equality practices based on the reasons for gender inequality in RDI organisations

\begin{tabular}{|c|c|}
\hline $\begin{array}{l}\text { Reasons for gender } \\
\text { inequality in RDI } \\
\text { organisations }\end{array}$ & $\begin{array}{l}\text { DM practices to address the organisational factors leading to gender } \\
\text { inequality }\end{array}$ \\
\hline $\begin{array}{l}\text { Historical reasons: the } \\
\text { focus on women in science } \\
\text { started relatively late }\end{array}$ & $\begin{array}{l}\text { - } \quad \text { Awareness raising campaigns on gender equality, and its } \\
\text { importance for internal and external stakeholders } \\
\text { - } \quad \text { Benchmarking studies with other industries on gender equality } \\
\text { - } \quad \text { Placing gender equality on the agenda in the organisation }\end{array}$ \\
\hline $\begin{array}{l}\text { Tall hierarchies, rigid } \\
\text { traditional career ladders } \\
\text { in universities and RDI } \\
\text { organisations }\end{array}$ & $\begin{array}{l}\text { - } \quad \text { Selection tools: Transparent promotion procedures; prioritising } \\
\text { research quality over quantity in selection criteria; briefing } \\
\text { promotion committees about bias pitfalls before the assessment; } \\
\text { including external observers and evaluators in these processes; } \\
\text { evaluating all selection and promotion procedures before } \\
\text { appointments are completed" (Gvozdanović - Maes 2018: 18) } \\
\text { - } \quad \text { Including women in selection committees } \\
\text { - } \quad \text { Expressing responsibility by leadership } \\
\text { - } \quad \text { Establishing target numbers or quotas for women for each career } \\
\text { stage }\end{array}$ \\
\hline $\begin{array}{l}\text { "Blindness" or low } \\
\text { awareness of gender or } \\
\text { other inequalities }\end{array}$ & $\begin{array}{l}\text { - Awareness raising campaigns on gender equality, and its } \\
\text { importance for internal and external stakeholders } \\
\text { Monitoring various indicators of gender equality within the } \\
\text { organisation and communicating it internally and/or externally } \\
\text { - Training for management and employees on unconscious gender } \\
\text { bias }\end{array}$ \\
\hline $\begin{array}{l}\text { Inequality regimes, } \\
\text { invisibility of gendered } \\
\text { practices, the legitimacy } \\
\text { of inequalities, arguments } \\
\text { that naturalise gender } \\
\text { inequalities, }\end{array}$ & 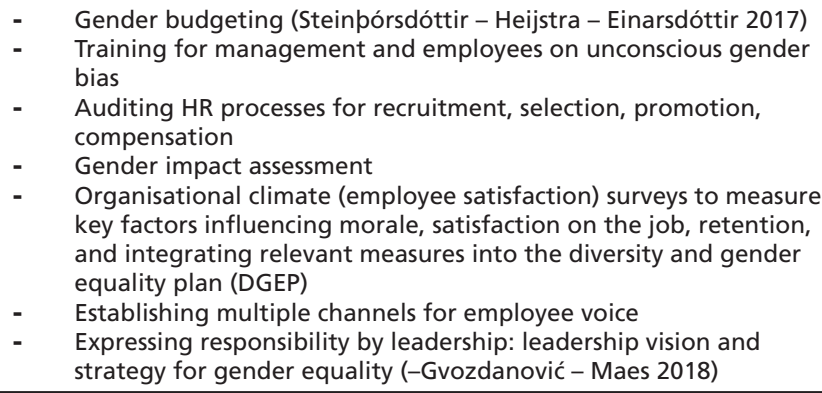 \\
\hline $\begin{array}{l}\text { Discrimination } \\
\text { (Intersectional } \\
\text { discrimination) }\end{array}$ & $\begin{array}{l}\text { - } \quad \text { Raising awareness about the different forms of discrimination } \\
\text { among employees and managers } \\
\text { - } \quad \begin{array}{l}\text { Auditing HR processes for recruitment, selection, promotion, } \\
\text { compensation }\end{array} \\
\text { - } \quad \begin{array}{l}\text { Including women and other minority group representatives into } \\
\text { selection and other committees }\end{array} \\
\text { - } \quad \text { Establishing quotas for under-represented groups to have a } \\
\text { balanced workforce composition } \\
\text { - Training on unconscious bias and stereotypes for management at } \\
\text { all levels }\end{array}$ \\
\hline $\begin{array}{l}\text { Performance expectations } \\
\text { (Double standards for } \\
\text { women and men) }\end{array}$ & $\begin{array}{ll}\text { - } & \text { Gender budgeting (Steinpórsdóttir - Heijstra - Einarsdóttir 2018) } \\
\text { - } & \text { More focus on quality of performance than quantity of } \\
\text { - } & \text { performance } \\
\text { - } \quad \text { Tranpensating for parental leave }\end{array}$ \\
\hline $\begin{array}{l}\text { Women's versus men's } \\
\text { networks } \\
\text { (women's exclusion from } \\
\text { men's networks) }\end{array}$ & $\begin{array}{l}\text { - } \quad \text { Mentoring and coaching } \\
\text { - Developing diversity networks (women, early career, single } \\
\text { parent, working parents, intersectional groups, and other } \\
\text { diversity groups) }\end{array}$ \\
\hline
\end{tabular}




\begin{tabular}{|c|c|}
\hline $\begin{array}{l}\text { Reasons for gender } \\
\text { inequality in RDI } \\
\text { organisations }\end{array}$ & $\begin{array}{l}\text { DM practices to address the organisational factors leading to gender } \\
\text { inequality }\end{array}$ \\
\hline $\begin{array}{l}\text { Expectations of brilliance } \\
\text { (Leslie, Cimpian, Meyer, - } \\
\text { Freeland, 2015) }\end{array}$ & $\begin{array}{l}\text { - Building partnerships with NGOs and primary and secondary } \\
\text { educational institutions to promote scientific careers for girls } \\
\text { - } \quad \text { Reaching out to university students: internships, open days, } \\
\text { building partnerships with universities and RPOs } \\
\text { - } \quad \text { Awareness raising campaigns on gender equality, and its } \\
\text { importance for internal and external stakeholders }\end{array}$ \\
\hline $\begin{array}{l}\text { Masculine/gendered } \\
\text { organisational culture, } \\
\text { masculine-stereotyped } \\
\text { patterns of on-the-job } \\
\text { behaviour } \\
\text { (Acker, 2006) }\end{array}$ & $\begin{array}{ll}\text { - } & \text { Organisational culture change processes } \\
\text { - } & \text { Gender impact assessment } \\
\text { - } & \text { Diversity in leadership } \\
\text { - } & \text { Leadership vision and strategy for gender equality (Gvozdanović } \\
\text { - } \quad \text { Maes 2018) } & \text { Training for management at all levels and employees on } \\
\text { unconscious gender bias } \\
\text { - Organisational climate (employee satisfaction) surveys to measure } \\
\text { key factors influencing morale, satisfaction on the job, retention, } \\
\text { and integrating relevant measures into the DGEP } \\
\text { Developing fact sheets, online resources, and other information } \\
\text { tools to increase knowledge about gender bias }\end{array}$ \\
\hline $\begin{array}{l}\text { Problems with work-life } \\
\text { balance, and lack of family- } \\
\text { friendly policies }\end{array}$ & 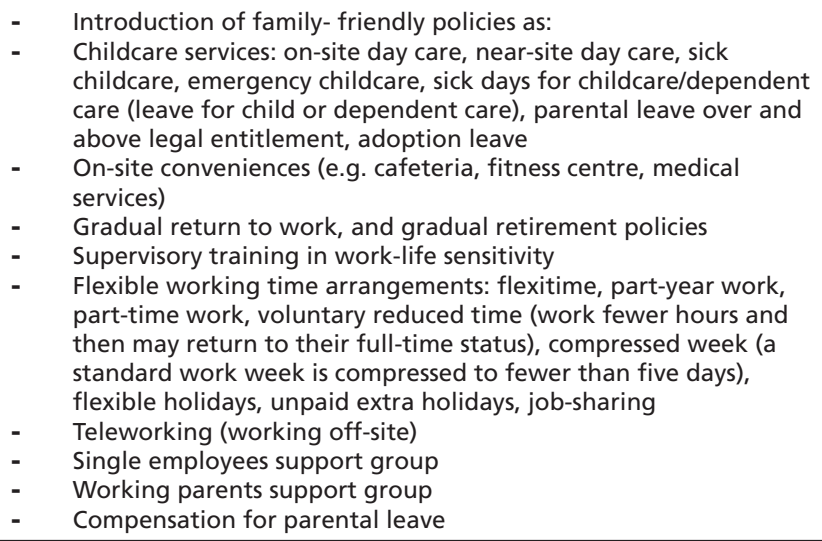 \\
\hline $\begin{array}{l}\text { Absence of effective } \\
\text { diversity management }\end{array}$ & $\begin{array}{l}\text { - } \quad \begin{array}{l}\text { Showing leadership, vision and strategy for gender equality } \\
\text { (Gvozdanović - Maes 2018). }\end{array} \\
\text { - } \quad \begin{array}{l}\text { A senior manager is designated to champion equality and } \\
\text { diversity in the organisation. }\end{array} \\
\text { - } \quad \begin{array}{l}\text { Incorporating diversity and equality strategies and targets in the } \\
\text { strategic planning process, identifying key performance indicators } \\
\text { related to gender equality and diversity (building on diversity and } \\
\text { innovation). }\end{array} \\
\text { - } \quad \begin{array}{l}\text { Hiring a person with DM and gender equality expertise on staff } \\
\text { (Diversity Manager). }\end{array} \\
\text { - } \quad \text { mstablishing a diversity taskforce with employee volunteers and } \\
\text { - } \quad \begin{array}{l}\text { Auditing current conditions of diversity and gender equality in } \\
\text { the organisation. }\end{array} \\
\text { - } \quad \text { Establishing a DGEP with measurable targets and deadlines. } \\
\text { Providing resources for the implementation of the diversity and } \\
\text { gender equality plan. } \\
\text { - } \quad \text { Identifying accountability for actions. } \\
\text { Establishing an effective communication strategy for the DGEP. } \\
\text { Monitoring the effectiveness of interventions planned in the } \\
\text { DGEP and set up new plan. }\end{array}$ \\
\hline
\end{tabular}

Sources: (Acker 2006; Ali - Konrad 2017; Gvozdanović - Maes 2018; Konrad - Mangel 2000; Leslie et al. 2015; Paksi 2015; 


\section{Outcomes of DM in business versus RDI organisations}

Measuring the impact and the outcomes of DM practices is of crucial importance to understand the social and business value of diversity interventions in organisations. Organisations can select from various measurement tools and diversity metrics such as the participation rate in initiatives, employment rate of minority groups at different organisational levels, employee satisfaction rate with diversity climate and diversity initiatives, intervention effectiveness related to pre-determined targets, cost and benefit of diversity initiatives, return on investment calculations of new diversity practices, and impact on business indicators to assess revenue, sales, customer satisfaction, profit rate, non-financial benefits of diversity, and national or international benchmarking. Companies can also establish diversity scorecards to assess the various indicators of DM impacts and outcomes (Hubbard 2012). In the next sections, we review different aspects of DM outcomes.

\section{DM outcomes: Competitive advantage - The Business case}

The idea of establishing a link between the DM practices and organisational performance was first observed in the resource-based perspective of the firm, in which resources that are valuable, rare, and inimitable, can be a source of sustained competitive advantage (Barney - Clark 2007). There is ample evidence for the positive relationship between DM and organisational performance. Using a sample of forprofit business organisations from the 1996 to 1997 National Organizations Survey in the United States, Herring (2009) observes supporting evidence that gender diversity is associated with increased sales revenue, more customers, and greater relative profits. Armstrong and colleagues (2010) observe that diversity equality management system practices are positively associated with higher labour productivity, workforce innovation, and lower voluntary employee turnover on the basis of quantitative data from service and manufacturing organisations in Ireland (Armstrong et al. 2010). Østergaard, Timmermans and Kristinsson (2011) investigate the impact of employee diversity on innovation. Based on an econometric analysis, the findings reveal a positive relation between diversity in education and gender on the likelihood of introducing an innovation. Furthermore, a positive relationship between an open culture towards diversity and innovative performance was supported by the data (Østergaard - Timmermans - Kristinsson 2011). On the other hand, Kochan et al. (2003) argue that conceptually, DM practices should be treated as a moderator of the association between the diversity of human capital and performance outcomes; however, they observe positive or negative direct effects of diversity on performance, indicating a more nuanced view of the business case for diversity when the aspects of the organisational context and group processes are also considered. Similarly, Mor Barak et al. (2016) based on a state-of-the-art review and meta-analysis of 30 studies on DM outcomes in human service organisations conclude that DM initiatives could lead to both beneficial and detrimental organisational outcomes. Their findings also 
demonstrate that workers' perceptions of DM efforts and inclusion climate have a positive impact on DM outcomes.

In the RDI sector, we observe much fewer examples of research on the relationship of DM practices and the increased level of organisational performance. The EFFORTI project (2017) identifies a positive relationship between the gender equality measures on academic performance and innovation on the national level. However, at the organisational level, we could not find evidence in the literature for the positive relationship between DM practices for gender equality and indicators of organisational performance, such as research excellence and innovation.

\section{DM outcomes: employment of designated groups}

In the business literature on DM practices and the employment of vulnerable groups, some authors have not identified a meaningful relationship between the two variables (Naff - Kellough 2003). Nevertheless, a much greater section of DM research has established a significant positive link between diversity management practices and the employment of designated groups (Kalev - Kelly - Dobbin 2006; Konrad - Linnehan 1995; Yang - Konrad 2011) Based on a sample of 816 firms in the United States over 23 years, Dobbin, Kim and Kalev (2011) analyse six selected diversity programmes: equal opportunity advertisement policies, diversity training for managers, general diversity training to all employees, affinity (diversity) networks that offer support and career advice, diversity taskforces, and diversity mentoring programmes. According to their findings, only diversity taskforces and diversity mentoring programmes had a positive impact on diverse employment statistics.

In the RDI sector, longitudinal studies have also identified a significant positive link between increase of DM practices and employment statistics of women within the organisation (Bilimoria - Joy - Liang 2008; Timmers - Willemsen - Tijdens 2010; Winchester- Browning 2015).

DM outcomes: vertical segregation - representation of designated groups at the top of the hierarchy

Research focusing on women in top management positions and on boards have mostly investigated the benefits of gender diversity at the top level of management in terms of organisational performance (Choudhury 2015; Kim - Starks 2016; Kumar - Zattoni 2016; Mensi-Klarbach 2014; Terjesen - Couto - Francisco 2016). Another stream of literature has focused on the barriers that prevent women from being promoted to top management positions. Notably, much less evidence is available on how DM practices contribute to women's promotions at the top levels of management. Nevertheless, Cook and Glass (2013) observe that diversity among decision makers significantly increased women's likelihood of receiving a promotion to a top leadership position.

Concerning the RDI sector, according to the longitudinal study of Timmers, Willemsen and Tijdens (2010), the Glass Ceiling Index, composed to measure the 
level of vertical segregation, decreases between 2000 and 2007 as a result of the implemented gender equality initiatives. The correlation between the Glass Ceiling Index and the rank of the university based on the number of gender policy measures showed a Spearman rho correlation, $r=0.35$. The larger the number of gender equality policy measures, the larger the reduction of the Glass Ceiling Index. Another important finding in Timmers, Willemsen and Tijdens (2010) is that the increase in the percentage of women among professors at universities in the Netherlands positively, strongly, and significantly correlates with the cultural perspective, that is, having women on selection committees, implementing gender impact assessments, expressing responsibility by management, training for management, and providing consultation rounds (Timmers - Willemsen - Tijdens 2010).

\section{Diversity practice outcomes: diversity training}

In the business sector, Alhejji and colleagues (2016) analyse diversity training outcomes based on a systematic literature review and identify three perspectives, namely, the business case, learning, and social justice perspectives, in interpreting the outcomes of diversity training. Von Bergen - Soper - Foster (2002) emphasise the role of quality control of diversity training providers to avoid negative effects of diversity training. According to a meta-analysis of 260 samples of diversity training evaluation, Bezrukova and colleagues (2016) identify positive effects for reactions to training and cognitive learning; nevertheless, the impact on behavioural and attitudinal changes is less important. Moreover, the positive effects of diversity training are greater when training is integrated with other diversity initiatives and targeted to awareness and skills development and conducted for a longer duration. (Bezrukova et al. 2016). Analysis of diversity training outcomes in the RDI sector are not found by the authors of this article.

\section{Diversity practice outcomes: mentoring}

Kalev and colleagues (2006) are among the first scientists to systematically analyse the efficacy of DM initiatives in business organisations. Their analyses rely on data describing the workforces of 708 private sector organisations from 1971 to 2002, together with survey data on their employment practices. According to their findings, efforts to moderate managerial bias through diversity training and diversity evaluations are least effective at increasing the proportion of White women, Black women, and Black men in management. Notably, efforts to reduce social isolation through mentoring and networking showed a modest impact. The greatest outcomes in managerial diversity could be associated with interventions aiming to establish responsibility for diversity. Moreover, organisations that establish responsibility for diversity and equality have better effects from diversity training and evaluations, networking, and mentoring than organisations that do not. Employers who assign responsibility for compliance to a manager also experience stronger effects from 
some diversity programmes. In summary, these results emphasise the importance of the institutional theory in the evaluation of the outcomes of diversity interventions (Kalev - Kelly - Dobbin 2006).

Regarding the RDI sector, Gardiner and colleagues (2007) evaluate a mentoring scheme for junior female academics to address the under-representation of women in senior positions by increasing participation in networks and improving women's research performance. They use a multifaceted, longitudinal design, including a control group to evaluate the outcome of mentoring for the women and the university. According to the results, mentoring is very beneficial because mentees are more likely to remain at the university, receive a higher amount of grants, experience higher levels of promotion, and have better self-perceptions of themselves as academics compared with non-mentored female academics (Gardiner et al. 2007).

In a qualitative study of 100 former recipients of the National Institutes of Health mentored career development awards and 28 of their mentors, DeCastro and colleagues identify three major themes: 1 ) the many roles and behaviours associated with mentoring, 2) the improbability of finding a single person to fulfil the diverse mentoring needs of another individual, and 3) the importance and composition of mentor networks. Many participants expressed their need to have more than one mentor, and female participants generally acknowledged the importance of having at least one female mentor. Some participants observed that their portfolio of mentors needed to evolve to remain effective. The authors conclude that the importance of developing mentoring networks is more essential than hierarchical mentoring pairs (DeCastro et al. 2013).

\section{Diversity practice outcomes: diversity networks}

Dennissen, Benschop and van den Brink (2016) study how diversity networks contribute to equality by examining how diversity network leaders discursively construct the value of their networks. On the basis of five different diversity networks in a financial service organisation in the Netherlands, their results show that network leaders tend to construct the value of their networks primarily in terms of individual career development and community building and are much less articulate about removing the barriers to inclusion in the organisation. The authors conclude that the value of diversity networks is limited in the sense that they focus mostly on individual and group levels of equality and unchallenge inequalities at the organisational level (Dennissen - Benschop - van den Brink 2016). Another problem identified with diversity networks is that they focus on single identity categories and thus marginalise members with multiple disadvantaged identities. (Dennissen - Benschop - van den Brink 2018).

Related to the RDI sector, Price, Coffey and Nethery (2015) evaluate the experiences of three early career academics attempting to establish a network of early career academics in a middle-ranked university in Australia. The authors' experiences 
suggest that high performance expectations create barriers to involvement in the network (Price - Coffey - Nethery 2015).

\section{DM outcomes: social responsibility, external legitimacy and reputation}

Bear, Rahman and Post (2010) explore how the diversity of the board and the number of women on boards affect firms' corporate social responsibility (CSR) ratings and how, in turn, CSR influenced corporate reputation. Their findings show that CSR ratings have a positive impact on reputation and mediate the relationship between the number of women on the board and corporate reputation (Bear - Rahman Post 2010). For organisations of the RDI sector, the external pressures to develop reputations based on gender diversity are less marked.

\section{Conclusions and future areas for research}

We have reviewed a substantial section of extant research papers on the development of DM, and we have especially focused on the stream of research focusing on academia and organisations in the RDI sector. The research question this article attempted to answer was as follows: How does DM contribute to gender equality in RDI workplaces? To answer this question, first, we reviewed how RDI organisations might address gender equality and diversity among researchers, and next, we categorised potential DM practices on the basis of whether they intend to counter forms and manifestations or the underlying reasons for gender inequality. Our ultimate goal was to understand the impact of various DM practices in terms of their effectiveness in attaining desired outcomes that aim to increase gender equality within RDI organisations.

Concerning the antecedents of DM, evidence in the research reveals that an open organisational culture, a positive diversity climate, a gender-diverse top management team, a high commitment to HR policies, and formal commitments to equalityrelated social norms are the most important antecedents for the implementation of DM practices. These antecedents are important enablers in the RDI sector, as well.

The literature review reinforces the assumption that DM practices, to be substantive, must include a good balance of individual, cultural, and organisational or structural level interventions in both the business and RDI sector. To manage the process of cultural and structural change effectively, leadership of RDI organisations must strongly adhere to gender equality values and social norms and demonstrate dedication, commitment, vision, and strategy. DM knowledge and expertise must be guaranteed within the organisation, and the regular practices of DM, for example, establishing a diversity taskforce, auditing current conditions of diversity and gender equality in the organisation, formulating a diversity and gender equality plan (DGEP) with measurable targets and deadlines, providing resources for the implementation of the diversity and gender equality plan, identifying accountability for actions, establishing an effective communication strategy for the DGEP, and monitoring 
the effectiveness of interventions planned in the diversity and gender equality plan prior to setting up a new plan. Similarly, to the business sector, RDI organisations could also incorporate diversity, equality strategies, and targets into their strategic planning process and identify key performance indicators related to gender equality and diversity to increase the effectiveness of DM initiatives.

By comparing the business and the RDI sector, we acknowledge that research on measuring the outcomes of DM practices is less developed for RDI organisations, but gaps of knowledge on the outcome of DM practices prevail in both sectors and represent topics for further research. The existence of a gap in the availability of research between the business and RDI sectors is especially marked concerning the overall link between DM practices and organisational performance to the benefits of research on business organisations. Conversely, research related to the outcomes of DM practices in the RDI sector is most developed regarding changes in employment statistics and vertical segregation of women. This literature review reinforces the importance of managing the organisational culture relative to gender equality to attain sustainable results (e.g. training management, gender impact assessment, expressing responsibility).

Concerning specific DM practices, most of the literature has investigated mentoring, diversity training, and diversity networks. Gender equality outcomes are identified for these practices and are positive or mixed. The organisational contexts in which these specific diversity practices are implemented have a significant role in determining the effectiveness of these practices, highlighting the relevance of the institutionalist theory. Notably, establishing a diversity taskforce or committee has a significant outcome for the employment of minority groups, including women. This phenomenon indicates that it is worthwhile for RDI organisations to allocate sufficient HRs to manage diversity.

Researchers on DM outcomes have differed in their approaches to how they address diversity practices: separately or in groups. Further research should not only focus on investigating the effectiveness of single diversity practices, but consider the outcomes of the bundles of gender diversity practices simultaneously, because the literature has identified a linear relationship between the number of DM practices implemented by RDI organisations and the improvements in reducing vertical segregation. Moreover, a strategic HR management perspective could be adopted in $\mathrm{RDI}$ organisations, by referring to the assumption that when different DM practices are bundled, the combinations may be difficult to imitate and may serve as a source of competitive advantage. Additionally, RDI organisations and further research could focus on attaining a deeper understanding of the relationship of gender equality and research excellence and innovations in RDI organisations.

Despite the prevailing gaps of research on the topic, overall, the evidence from this literature review suggests that though RDI sector organisations have specific barriers related to gender equality as rigid traditional career ladders, blindness or low awareness 
of gender inequalities, and masculine/gendered organisational culture, nevertheless the methodologies and practices of DM available in the business sector could yield comparable results in terms of gender equality outcomes in the RDI sector as well if RDI organisations adopt approaches to change in a systematic manner focusing on balancing individual, cultural, and structural level interventions for gender equality.

\section{References}

Abrams, K. (1989): Gender discrimination and the transformation of workplace norms. Vand. L. Rev, 42: 1183.

Acker, J. (2006): Inequality regimes: Gender, class, and race in organizations. GenderSociety, 20 (4): 441-464. https://doi.org/10.1177/0891243206289499

Alhejji, H. - Garavan, T. - Carbery, R. - O’Brien, F. - McGuire, D. (2016): Diversity training programme outcomes: A systematic review. Human Resource Development Quarterly, 27 (1): 95-149. https://doi.org/10.1002/hrdq.21221

Ali, M. - Konrad, A. M. (2017): Antecedents and consequences of diversity and equality management systems: The importance of gender diversity in the TMT and lower to middle management. European Management Journal, 35 (4): 440-453. https://doi.org/10.1016/j.emj.2017.02.002

Armstrong, C. - Flood, P. C. - Guthrie, J. P. - Liu, W. - MacCurtain, S. - Mkamwa, T. (2010): The impact of diversity and equality management on firm performance: Beyond high performance work systems. Human Resource Management, 49 (6): 977-998. https://doi.org/10.1002/hrm.20391

Barney, J. B. - Clark, D. N. (2007): Resource-based theory: Creating and sustaining competitive advantage. Oxford: Oxford University Press on Demand.

Bear, S. - Rahman, N. - Post, C. (2010): The impact of board diversity and gender composition on corporate social responsibility and firm reputation. Journal of Business Ethics, 97 (2): 207-221.

Bezrukova, K. - Spell, C. S. - Perry, J. L. - Jehn, K. A. (2016): A meta-analytical integration of over 40 years of research on diversity training evaluation. Psychological Bulletin, 142 (11): 1227.

Bilimoria, D. - Joy, S. - Liang, X. (2008): Breaking barriers and creating inclusiveness: Lessons of organizational transformation to advance women faculty in academic science and engineering. Human Resource Management, 47 (3): 423-441. https:// doi.org/10.1002/hrm.20225

Bleijenbergh, I. - Peters, P. - Poutsma, E. (2010): Diversity management beyond the business case. Equality, Diversity and Inclusion: An International Journal, 29 (5): 413-421. https://doi.org/10.1108/02610151011052744 
Bryson, C. (2004): The consequences for women in the academic profession of the widespread use of fixed term contracts. Gender, Work \& Organization, 11 (2): 187206. https://doi.org/10.1111/j.1468-0432.2004.00228.x

Card, D. - Cardoso, A. R. - Kline, P. (2015): Bargaining, sorting, and the gender wage gap: Quantifying the impact of firms on the relative pay of women. The Quarterly Journal of Economics, 131 (2): 633-686. https://doi.org/10.1093/qje/qjv038

Choudhury, B. (2015): Gender diversity on boards: Beyond quotas. European Business Law Review, 26 (1): 229-243.

Cleveland, J. N. - Stockdale, M. - Murphy, K. R. - Gutek, B. A. (2000): Gender Discrimination in the Workplace. In Cleveland, J. N. - Stockdale, M. - Murphy, K. R. - Gutek, B. A. (2000): Women and Men in Organizations. Sex and Gender Issues at Work, 169-198. New York: Psychology Press

Cook, A. - Glass, C. (2013): Women and Top Leadership Positions: Towards an Institutional Analysis. Gender, Work \& Organization, 21 (1): 91-103. https://doi. org/10.1111/gwao.12018

Cox Jr, T. (1991): The multicultural organization. Academy of Management Perspectives, 5 (2): 34-47. https://doi.org/10.5465/ame.1991.4274675

Dämmrich, J. - Blossfeld, H.-P. (2016): Women's disadvantage in holding supervisory positions. Variations among European countries and the role of horizontal gender segregation. Acta Sociologica, 60 (3): 262-282. https://doi. org/10.1177/0001699316675022

DeCastro, R. - Sambuco, D. - Ubel, P. A. - Stewart, A. - Jagsi, R. (2013): Mentor Networks in Academic Medicine: Moving Beyond a Dyadic Conception of Mentoring for Junior Faculty Researchers. Academic Medicine: Journal of the Association of American Medical Colleges, 88 (4): 488-496. https://doi.org/10.1097/ ACM.0b013e318285d302

Dennissen, M. - Benschop, Y. - van den Brink, M. (2016): Diversity Networks: Networking for Equality? British Journal of Management, 00: 1-15. https://doi. org/10.1111/1467-8551.12321

Dennissen, M. - Benschop, Y. - van den Brink, M. (2018): Rethinking Diversity Management: An Intersectional Analysis of Diversity Networks. Organization Studies, 1-22. https://doi.org/10.1177/0170840618800103

Dobbin, F. - Kim, S. - Kalev, A. (2011): You Can't Always Get What You Need: Organizational Determinants of Diversity Programs. American Sociological Review, 76 (3): 386-411. https://doi.org/10.1177/0003122411409704

Eckstein, Z. - Wolpin, K. I. (1999): Estimating the Effect of Racial Discrimination on First Job Wage Offers. The Review of Economics and Statistics, 81 (3): 384-392. https://doi.org/10.1162/003465399558319

EFFORTI. (2017): Comparative Background Report. Main Findings. STEM Gender Equality Congress Proceedings, 1 (1): 858-858. https://doi. org/10.21820/25150774.2017.1.57 
Ely, R. J. - Thomas, D. A. (2001): Cultural Diversity at Work: The Effects of Diversity Perspectives on Work Group Processes and Outcomes. Administrative Science Quarterly, 46 (2): 229-273. https://doi.org/10.2307/2667087

European Commission. (Ed.). (2009): The gender challenge in research funding: assessing the European national scenes; report. Luxembourg: Office for Official Publ. of the European Communities

European Commission. (2012): A Reinforced European Research Area Partnership for Excellence and Growth. Retrieved 9 October 2018, from https://ec.europa.eu/ digital-single-market/en/news/reinforced-european-research-area-partnershipexcellence-and-growth

European Commission. (2015): European Research Area facts and figures 2014. Luxembourg: Publications Office. Retrieved from http://bookshop.europa.eu/ur i?target=EUB:NOTICE:KIAU26803:EN:HTML

European Commission. (Ed.) (2016): She figures 2015. Luxembourg: Publications Office of the European Union

European Parliament, C. on W. R. and G. E. (2015): Report on women's careers in science and universities, and glass ceilings encountered. European Parliament, 19.

European Union. (2017): 2017 report on equality between women and men in the EU. Retrieved from https://eeas.europa.eu/sites/eeas/files/2017_report_equality_ women_men_in_the_eu_en.pdf

Ferrari, R. (2015): Writing narrative style literature reviews. Medical Writing, 24 (4): 230-235. https://doi.org/10.1179/2047480615Z.000000000329

Gardiner, M. - Tiggemann, M. - Kearns, H. - Marshall, K. (2007): Show me the money! An empirical analysis of mentoring outcomes for women in academia. Higher Education Research - Development, 26 (4): 425-442. https://doi. org/10.1080/07294360701658633

Gash, V. - McGinnity, F. (2007): Fixed-term contracts - the new European inequality? Comparing men and women in West Germany and France. Socio-Economic Review, 5 (3): 467-496. https://doi.org/10.1093/ser/mwl020

Grant, M. J. - Booth, A. (2009): A typology of reviews: an analysis of 14 review types and associated methodologies. Health Information - Libraries Journal, 26 (2): 91108.

Gvozdanović, J. - Maes, K. (2018): Implicit bias in academia: A challenge to the meritocratic principle and to women's careers-and what to do about it (Advice paper No. Technical Report 23) Leuven: League of European Research Universities (LERU), 28.

Herdman, A. O. - McMillan-Capehart, A. (2010): Establishing a Diversity Program is Not Enough: Exploring the Determinants of Diversity Climate. Journal of Business and Psychology, 25 (1): 39-53. https://doi.org/DOI 10.1007/s10869-009-9133-1

Herring, C. (2009): Does Diversity Pay?: Race, Gender, and the Business Case for Diversity. American Sociological Review, 74 (2): 208-224. https://doi. org/10.1177/000312240907400203 
Hubbard, E. (2012): The Diversity Scorecard. Routledge. https://doi. org/10.4324/9780080470061

Kacprzak, A. (2014): Determinants of Vertical and Horizontal Gender Segregation in the Workplace in Poland. https://doi.org/10.15678/AOC.2014.1105

Kalev, A. - Kelly, E. - Dobbin, F. (2006): Best Practices or Best Guesses? Assessing the Efficacy of Corporate Affirmative Action and Diversity Policies. American Sociological Review, 71 (4): 589-617.

Kandola, R. S. - Fullerton, J. (1998): Diversity in action: Managing the mosaic. London: CIPD Publishing

Kangasniemi, M. - Kauhanen, A. (2013): Performance-related pay and gender wage differences. Applied Economics, 45 (36): 5131-5143. https://doi.org/10.1080/000 36846.2013.824546

Kelly, E. - Dobbin, F. (1998): How Affirmative Action Became Diversity Management: Employer Response to Antidiscrimination Law, 1961 to 1996. American Behavioral Scientist, 41 (7): 960-984. https://doi.org/10.1177/0002764298041007008

Kim, D. - Starks, L. T. (2016): Gender diversity on corporate boards: Do women contribute unique skills? American Economic Review, 106 (5): 267-271. https://doi. org/10.1257/aer.p20161032

Kochan, T. - Bezrukova, K. - Ely, R. - Jackson, S. - Joshi, A. - Jehn, K. - Thomas, D. (2003): The effects of diversity on business performance: Report of the diversity research network. Human Resource Management: Published in Cooperation with the School of Business Administration, The University of Michigan and in Alliance with the Society of Human Resources Management, 42 (1): 3-21. https://doi.org/10.1002/ hrm.10061

Konrad, A. M. - Linnehan, F. (1995): Formalized HRM structures: coordinating equal employment opportunity or concealing organizational practices? Academy of Management Journal, 38 (3): 787-820.

Konrad, A. M. - Mangel, R. (2000): The impact of work-life programs on firm productivity. Strategic Management Journal, 21 (12): 1225-1237. https://doi. org/10.1002/1097-0266(200012)21:12<1225::AID-SMJ135>3.0.CO;2-3

Kulik, C. T. (2014): Working below and above the line: the research-practice gap in diversity management. Human Resource Management Journal, 24 (2): 129-144. https://doi.org/10.1111/1748-8583.12038

Kumar, P. - Zattoni, A. (2016): Corporate Governance, Board Gender Diversity and Firm Performance. Corporate Governance: An International Review, 24 (4): 388-389. https://doi.org/10.1111/corg.12172

Leslie, S.-J. - Cimpian, A. - Meyer, M. - Freeland, E. (2015): Expectations of brilliance underlie gender distributions across academic disciplines. Science, 347 (6219), 262-265. https://doi.org/10.1126/science.1261375 
Mensi-Klarbach, H. (2014): Gender in top management research: Towards a comprehensive research framework. Management Research Review, 37 (6): 538552.

Meulders, D. - Plasman, R. - Rigo, A. - O’Dorchai, S. (2010): Horizontal and vertical segregation. Meta-Analysis of Gender and Science Research-Topic Report, 123. Http://Www. Genderandscience. Org/Doc/TR1_Segregation. Pdf. Retrieved from http://genport.uoc.edu/sites/default/files/resource_pool/TR1_Segregation.pdf

Mihaila, R. (2016): Is the Decrease in the Gender Wage Gap the Principal Driver of the Sustained Rise in Female Labor Market Participation? Journal of Research in Gender Studies, 6 (2): 146.

Mor Barak, M. E. - Lizano, E. L. - Kim, A. - Duan, L. - Rhee, M.-K. - Hsiao, H.Y. - Brimhall, K. C. (2016): The Promise of Diversity Management for Climate of Inclusion: A State-of-the-Art Review and Meta-Analysis. Human Service Organizations: Management, Leadership - Governance, 40 (4): 305-333. https://doi. org/10.1080/23303131.2016.1138915

Naff, K. C. - Kellough, J. E. (2003): Ensuring employment equity: Are federal diversity programs making a difference? International Journal of Public Administration, 26 (12): 1307-1336. https://doi.org/10.1081/PAD-120024399

OECD. (2017): Report on the Implementation of the OECD Gender Recommendations Some Progress on Gender Equality but Much Left to Do. Paris: OECD. Retrieved from http://www.oecd.org/mcm/documents/C-MIN-2017-7-EN.pdf

Østergaard, C. R. - Timmermans, B. - Kristinsson, K. (2011): Does a different view create something new? The effect of employee diversity on innovation. Research Policy, 40 (3): 500-509. https://doi.org/10.1016/j.respol.2010.11.004

Paksi, V. (2015): Work-life balance of female PhD students in engineering. In Pusztai, G. - Engler, Á. - Markóczi R. (Eds.): Development of Teacher Calling in Higher Education. Nagyvárad-Budapest: Partium Press-Personal Problems Solution-Új Mandátum, 179-194.

Poggio, B. (2017): Women and Men in Scientific Careers: New Scenarios, Old Asymmetries. PO, 5-16. https://doi.org/10.1424/86077

Price, E. - Coffey, B. - Nethery, A. (2015): An early career academic network: What worked and what didn't. Journal of Further and Higher Education, 39 (5): 680-698. https://doi.org/10.1080/0309877X.2014.971106

Prügl, E. (2011): Diversity Management and Gender Mainstreaming as Technologies of Government. Politics - Gender, 7 (1): 71-89. https://doi.org/10.1017/ S1743923X10000565

Robinson, G. - Dechant, K. (1997): Building a business case for diversity. Academy of Management Perspectives, 11 (3): 21-31. https://doi.org/10.5465/ ame.1997.9709231661

Standing, G. (2011): The Precariat. The New Dangerous Class. London: Bloomsbury Academic. 
Steinpórsdóttir, F. S. - Heijstra, T. M. - Einarsdóttir, D. J. (2017): The making of the'excellent'university: A drawback for gender equality. Ephemera, 17 (3): 557582.

Tardos, K. (2011): Esélyegyenlöség és sokszínüség a munkahelyeken (Equal Opportunities and Diversity at the Workplace). Budapest: mtd Tanácsadói Közösség.

Tatli, A. (2010): A Multi-layered Exploration of the Diversity Management Field: Diversity Discourses, Practices and Practitioners in the UK. British Journal of Management, 22 (2): 238-253.https://doi.org/10.1111/j.1467-8551.2010.00730.x

Terjesen, S. - Couto, E. B. - Francisco, P. M. (2016): Does the presence of independent and female directors impact firm performance? A multi-country study of board diversity. Journal of Management - Governance, 20 (3): 447-483. https://doi. org/10.1007/s10997-014-9307-8

Timmers, T. M. - Willemsen, T. M. - Tijdens, K. G. (2010): Gender diversity policies in universities: a multi-perspective framework of policy measures. Higher Education, 59 (6): 719-735. https://doi.org/10.1007/s10734-009-9276-z

Von Bergen, C. W. - Soper, B. - Foster, T. (2002): Unintended Negative Effects of Diversity Management. Public Personnel Management, 31 (2): 239-251. https:// doi.org/10.1177/009102600203100209

Winchester, H. P. - Browning, L. (2015): Gender equality in academia: A critical reflection. Journal of Higher Education Policy and Management, 37 (3): 269-281. https://doi.org/10.1080/1360080X.2015.1034427

Yang, Y. - Konrad, A. M. (2011): Understanding diversity management practices: Implications of institutional theory and resource-based theory. Group-Organization Management, 36 (1): 6-38. https://doi.org/10.1177/1059601110390997

Zanoni, P. - Janssens, M. - Benschop, Y. - Nkomo, S. (2010): Guest editorial: Unpacking diversity, grasping inequality: Rethinking difference through critical perspectives. Organization, 17 (1): 9-29. https://doi.org/10.1177/1350508409350344 